\title{
Association between nutritional status and outcome of childhood acute lymphoblastic leukemia treated with Wijaya Kusuma Protocol
}

\author{
Fransiska Herintya, Sri Mulatsih, Endy Paryanto Prawirohartono
}

\begin{abstract}
Background Acute lymphoblastic leukemia (ALL) is the most common malignancy in childhood. Malnutrition in malignancy patients including ALL is one of major problems. This condition is found at the time of diagnosis as a result of the disease itself or after, chemotherapy or radiation. Many studies have been conducted to determine the relationship between nutritional state and outcome of childhood ALL patients but the result was still controversial.

Objective To determine relative risk of death and relapse in childhood standard-risk ALL who received therapy using Wijaya Kusuma protocol.

Methods This was a retrospective cohort study. Newly-diagnosed patients since May 1999-December 2004 were taken for this study. Body mass index was used to measure nutritional status for $>2$ years old children, and weight-for-height was used for those of $=2$ years old. Data was obtained from Yogyakarta Pediatric Cancer Registry Dr. Sardjito Hospital. Chi-squared test was used to analyze the proportion difference and risk relative was used to determine risk for death and relapse.

Results One-hundred and forty five patients included in this study. There was no association between nutritional state and relapse (RR 1.1, 95\% CI 0.76;1.61). Logistic regression analysis showed that there was association between nutritional state and death (RR 2.34, 95\% CI 1.01;5.45). Sepsis and relapse have contribution to death as well (RR 6.75, 95\% CI 2.9;15.4 and RR 3.2, 95\% CI 1. 3;8.08 respectively).

Conclusion Nutritional status is not associatiated with relapse but is associated with death of ALL children. [Paediatr Indones 2008;48:28-32].
\end{abstract}

Keywords: acute lymphoblastic leukemia, nutritional status, relapse, death

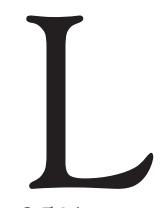

eukemia is the most common pediatric malignancy, ${ }^{1,2}$ approximately $23 \%$ among cancers which were diagnosed in children under 15 year of age. ${ }^{3}$ During 2000-2004, $35 \%$ patients were diagnosed as acute lymphoblastic leukemia (ALL) among 486 cancer patients hospitalized in Dr. Sardjito Hospital. ${ }^{4}$ Malnutrition is still a major problem in pediatric malignancy, and it was found in $8 \%$ among newly-diagnosed patients up to $50 \%$ in advanced disease. ${ }^{5}$ Many studies have been conducted to investigate the association between nutritional status and outcome of therapy in ALL patients, but the results remain controversy. Those studies had differences in methods, treatment protocols, and measurements of nutritional status. ${ }^{6-11}$.

The objective of this study was to determine the risk of death and relapse among pediatric ALL patients with undernutrition who got therapy using Wijaya Kusuma protocol.

From The Department of Child Health, Medical School, Gadjah Mada University, Yogyakarta, Indonesia.

Reprint requests to: Fransiska Herintya, MD, Department of Child Health, Medical School, Gadjah Mada University, Sardjito Hospital, Jl. Kesehatan no.1, Sekip Utara, Yogyakarta 55281, Indonesia. Tel. 62-274-587333. Fax. 62-274-587333. 


\section{Methods}

This retrospective study was conducted in Department of Child Health, Gadjah Mada University, Dr. Sardjito Hospital on pediatric ALL patients diagnosed between January 2000 - December 2004. Data were obtained from Yogyakarta Pediatric Cancer Registry, Dr. Sardjito Hospital. The inclusion criteria were children 0-15 years old with newly diagnosed ALL, never got chemotherapy before, and got Wijaya Kusuma protocol. Subjects were excluded from the study if they had no complete data or never visited the hospital for routine examinations.

Anthropometric measurement was conducted to assess nutritional status using CDC 2000 chart. Body mass index (BMI) was used for children $\geq 2-15$ years old and weight for height ratio (Wt/Ht) for $<2$ year old children. Children $\geq 2-15$ years old were considered as undernourished if BMI below 5 percentile CDC 2000 chart while children $<2$ year old if $\mathrm{Wt} / \mathrm{Ht}$ ratio was $60-79.9 \%$. Children $\geq 2-15$ years old were considered as well-nourished if BMI was between 5-95 percentile CDC 2000 chart. Children $<2$ year old were considered as well-nourished if $\mathrm{Wt} / \mathrm{Ht}$ ratio was $80-120 \%$. The patients were classified in three groups according to risk factors i.e, $<12$ months, $\geq 12-<120$ months, and $\geq 120$ months.

Relapse was defined as presenting blast $>20 \%$ of 200 nucleated cells in bone marrow, and/or presenting blast in peripheral blood smear, and/or presenting blast in liquor cerebrospinal, and/or lymphoblast infiltration to other organs. Death could occur in any phase during therapy.

Chi-squared test was used to determine proportion between two groups, and risk relative was used to determine the risk of death and relapse.

\section{Results}

During January 2000 - December 2004, there were 178 newly-diagnosed ALL patients. Five patients were excluded because they were older than 15 years of age, 12 patients diagnosed as L3 or Mixed ALL six patients had chemotherapy (dexamethasone) before, five patients refused to get chemotherapy, one patient had AML, and one patient died before therapy started. The flow chart of study was described as follows.

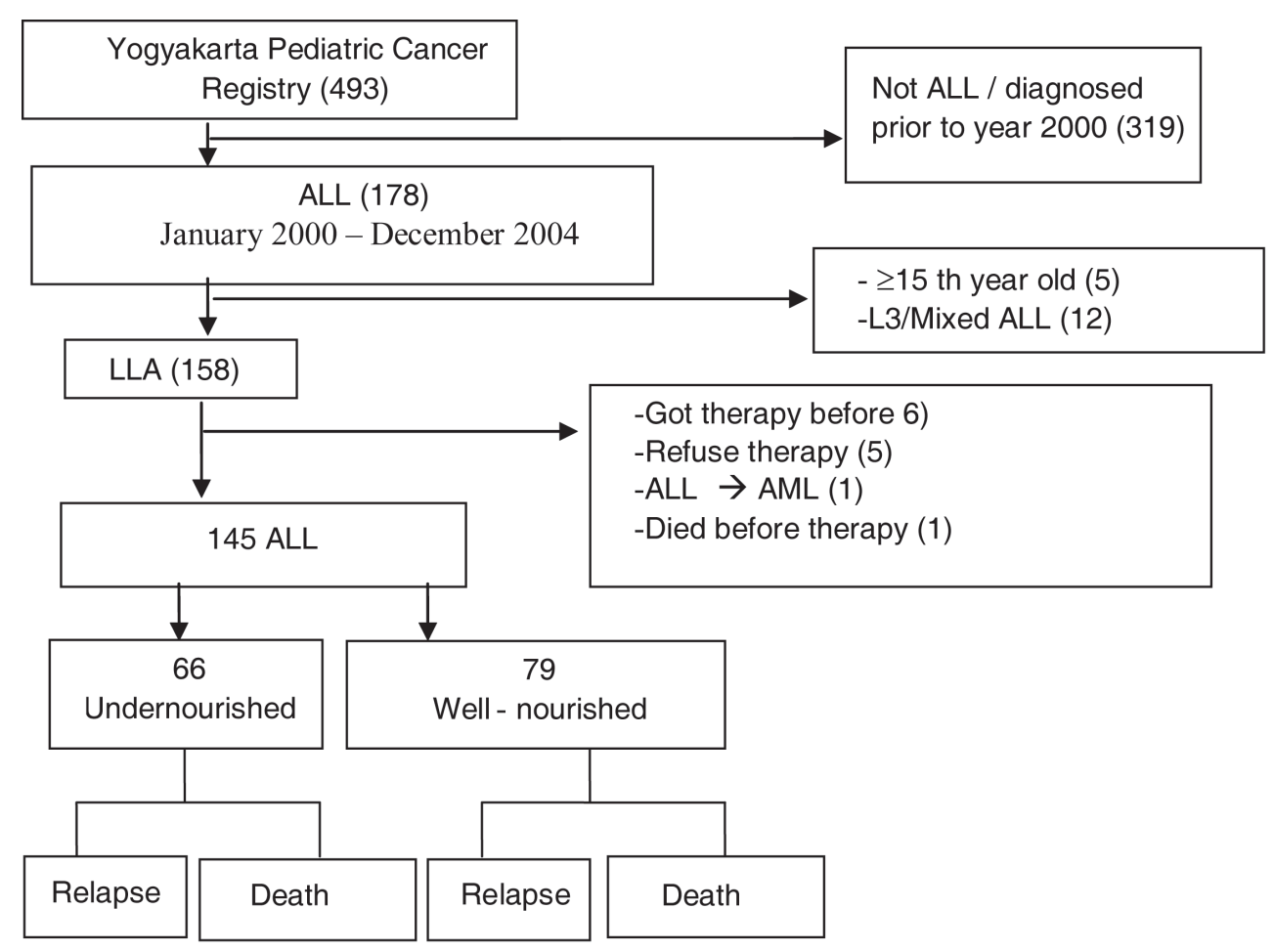

Figure 1. Study Algorithm 
In this study, there were 90 (62.1\%) boys, and $55(27.9 \%)$ girls. Most of them are $\geq 1-10$ years old. Sixty-six (45.5\%) patients were undernourished and 79 (54.5\%) were well-nourished. Thirty six percent were included in high risk, and $63.4 \%$ in standard risk group. Baseline characteristics are described in the Table 1.

During induction phase, $100 \%$ got remission but 14 patients $(9.6 \%)$ drop out and 20 patients (13.8\%) died. Five patients were undernourished, and 15 patients were well-nourished. There was no

Table 1. Baseline Characteristics

\begin{tabular}{lcccc}
\hline & \multicolumn{2}{c}{ Undernourished } & \multicolumn{2}{c}{ Well-nourished } \\
& $\mathrm{n}$ & $\%$ & $\mathrm{n}$ & $\%$ \\
\hline $\begin{array}{l}\text { Gender } \\
\quad \text { Boys }\end{array}$ & 42 & 63.6 & 48 & 60.7 \\
$\quad$ Girls & 24 & 36.4 & 31 & 39.2 \\
Age & & & & \\
$\quad<12$ months old & 2 & 0.3 & 0 & 0 \\
$\quad 312-<120$ months & 56 & 84.8 & 70 & 88.6 \\
$\quad 120$ months old & 8 & 12.1 & 9 & 11.4 \\
Risk & & & & \\
$\quad$ Standard risk & 38 & 57.5 & 54 & 68.3 \\
$\quad$ High risk & 28 & 42.5 & 25 & 31.7 \\
\hline
\end{tabular}

significant difference (RR 0.57, 95\%CI 0.25;1.11). There was no significant difference either in standard and high risk groups (RR 1.27, 95\%CI $0.74 ; 2.19)$.

Outcome after induction phase is described in Table 2. Based on nutritional status, there was no significant difference both in death (RR 0.94, 95\% CI $0.64 ; 1.38)$ and relapse (RR $1.1,95 \%$ CI $0.76 ; 1.61)$. There was no significant difference either in death both in high risk and standard risk groups (RR 1.12, 95\% CI 0.72;1.75) and similar results were found in relapse as well (RR 1.1, 95\% CI $0.76 ; 1.61)$.

Overall, the results of this study are described in Table 3. It is seen in Table 3 that there was no association between nutritional status and outcome therapy (death and relapse). We conducted multivariate analysis using logistic regression. The results are described in Table 4. Table 4 shows that sepsis, risks factors and nutritional status had contribution to cause death. Patients with undernourished had risk for death 2.34 compared to well-nourished (95\% CI 1.01;5.45).

Table 2. Outcome after induction phase

\begin{tabular}{lccccccc}
\hline & \multicolumn{2}{c}{ Under nourished } & \multicolumn{2}{c}{ Well-nourished } & RR & $95 \% \mathrm{Cl}$ & $\mathrm{P}$ \\
& $\mathrm{n}$ & $\%$ & $\mathrm{n}$ & $\%$ & & & \\
\hline Death & 21 & 37.9 & 27 & 48.2 & 0.94 & $0.64 ; 1.38$ & 0.76 \\
Alive & 34 & 62.1 & 29 & 51.8 & & & \\
Relapse & 21 & 31.8 & 22 & 27.8 & 1.1 & $0.76 ; 1.61$ & 0.6 \\
No relapse & 45 & 68.3 & 57 & 72.2 & & & \\
Drop out & 11 & 16.7 & 4 & 5.7 & & & \\
\hline
\end{tabular}

Table 3. Outcome during therapy

\begin{tabular}{|c|c|c|c|c|c|c|c|}
\hline & \multicolumn{2}{|c|}{ Under nourished } & \multicolumn{2}{|c|}{ Well-nourished } & \multirow[t]{2}{*}{$\mathrm{RR}$} & \multirow[t]{2}{*}{$95 \% \mathrm{Cl}$} & \multirow[t]{2}{*}{$P$} \\
\hline & $\mathrm{n}$ & $\%$ & $\mathrm{n}$ & $\%$ & & & \\
\hline \multicolumn{8}{|l|}{ High risk } \\
\hline Death & 13 & 19.6 & 15 & 18.9 & 0.8 & $0.46 ; 1.28$ & 0.32 \\
\hline Alive & 15 & 22.7 & 10 & 12.6 & & & \\
\hline Relapse & 9 & 13.6 & 8 & 10.1 & 1.00 & $0.58 ; 1.72$ & 0.9 \\
\hline No relapse & 19 & 28.7 & 17 & 21.5 & & & \\
\hline Remmision & 21 & 39.6 & 14 & 26.4 & & & \\
\hline No remmision & 7 & 13.2 & 11 & 20.8 & & & \\
\hline Drop out & 12 & 22.6 & 9 & 17.3 & & & \\
\hline \multicolumn{8}{|l|}{ Standard risk } \\
\hline Death & 13 & 19.6 & 27 & 34.9 & 0.7 & $0.39 ; 1.14$ & 0.13 \\
\hline Alive & 25 & 37.8 & 27 & 34.9 & & & \\
\hline Relapse & 12 & 18.1 & 14 & 17.7 & 1.17 & $0.70 ; 1.95$ & 0.5 \\
\hline No relapse & 26 & 39.3 & 40 & 50.6 & & & \\
\hline Remmision & 33 & 35.9 & 38 & 41.3 & & & \\
\hline No remmision & 5 & 5.4 & 16 & 17.4 & & & \\
\hline Drop out & 9 & 9.8 & 10 & 10.9 & & & \\
\hline
\end{tabular}


Fransiska Herintya et al: Nutritional status and outcome of acute lymphoblastic leukemia

Table 4. Logistic regression of cause of death

\begin{tabular}{lccc}
\hline & \multicolumn{3}{c}{ Death } \\
& Variables & RR & $95 \% \mathrm{Cl} \mathrm{P}$ \\
\hline Sepsis & 6.75 & $2.9 ; 15.4$ & 0.00 \\
Relapse & 3.2 & $1.3 ; 8.08$ & 0.01 \\
Risks (HR and SR) & 1.9 & $0.84 ; 4.73$ & 0.11 \\
Nutritional status & 2.34 & $1.01 ; 5.45$ & 0.0 \\
\hline
\end{tabular}

\section{Discussion}

High prevalence of undernourish in ALL patients was similar with that of Viana et $a l^{6}$ study. Other author stated that in some patients who had undernourish at the time of diagnosis, had weight gain during the course of disease. ${ }^{12}$ Baseline characteristics showed that most of patients in this study were male and their age were 1-10 year old, and this is similar with that of the previous data. ${ }^{13}$ Even though BMI had sensitivity to assess nutritional status in children with malignancy, ${ }^{9}$ The method of assessing nutritional status can be erroneous because it doesn't consider hepatomegaly and splenomegaly. Children with normal Wt//Ht could have arm circumference less than standard. ${ }^{14}$

There is no significant difference in early death between undernourished and well-nourished patients. This is similar with that of previous study. ${ }^{7,9}$ Most of deaths in early phase are due to sepsis and it occur more in well-nourished children. Death after induction is mostly caused by the disease and patient's compliance. Other factors that influence death after induction phase were sepsis, intracranial bleeding, and relapse. All patients who suffered from intracranial bleeding died. Logistic regression anal-ysis showed that sepsis had the largest contribution to cause death (RR $6.75,95 \%$ CI 2.9;15.4), while nutritional status contributed with RR 2.34 (95\% CI 1.01;5.45). It is similar with that of previous study. 6,8 The reason why undernourished children have worse prognosis compared to well-nourished ones is that undernutrition leads to diminished bone marrow reserve that causes suboptimal doses of maintenance chemotherapy. Five year disease free survival of children received low doses MTX was $7 \%$ compared to $65 \%$ of those who received full doses. ${ }^{8}$

In conclusion nutritional status doesn't have association with relapse, but it has association with death. Other factors that have contribution to death are sepsis and relapse.

\section{Reference}

1. Gurney JG, Severson RK, Davis S \& Robison LL. Incidence of cancer in children in the United States. Sex, race, and 1year age-specific rates by histological type. Cancer 1995;75: 2186-95.

2. Friedmann AM, Weinstein HJ. The Role of Prognostic Feature in Treatment of Childhood Acute Lymphoblastic Leukemia. The Oncologist 2000;3:321-8.

3. Ries LA, Kosary CL, Hankey BF. SEER Cancer Statistics Review, 1973-1996. Bethesda, Md: National Cancer Institute.

4. Mulatsih S, Sumadiono, Sutaryo, Purwanto. The Result of Treating Children's Acute Lymphoblastic Leukemia (ALL) in Dr. Sardjito Hospital With WK-ALL Protocol 1999 - 2002. Bulletin Ilmu Kesehatan Anak 2005;17:808-19.

5. Yu LC. Nutrition and childhood malignancies. In: Suskin RM, Lewinter-Suskind L, editors. Textbook of pediatric nutrition. $2^{\text {nd }}$ ed. New York: Raven Press Ltd;1993. p. 41724.

6. Viana M, Murao M, Ramos G. Malnutrition as a prognostic factor in lymphoblastic leukemia: a multivariate analysis. Arch Dis Child 1994;71:304-10.

7. Mejia-Arangure JM, Fajardo-Gutierrez A, Reyes-Ruiz NI, Bernaldez-Rios R, Mejia-Dominguez AM, NavarreteNavarro S, et al. Malnutrition in childhood lymphoblastic leukemia: a predictor of early mortality during the inductionto-remission phase of the treatment. Arch Med Res 1999;30:150-3.

8. Lobato-Mendizabal E, Lopez-Martinez B, Ruiz-Arguelles GJ. A critical review of the prognostic value of the nutritional status at diagnosis in the outcome of therapy of children with acute lymphoblastic leukemia. Rev Invest Clin 2003;55:315.

9. Weir J, Reilly JJ, McColl JH, Gibson BE. No evidence for an effect of nutritional status at diagnosis on prognosis in children with acute lymphoblastic leukemia. J Pediatr Hematol Oncol 1998;20:534-8.

10. Kahn R, Sheikh MH, Inthekab K. Does weight for age have prognostic significance in children with acute lymphoblastic leukemia? Pak J Med Sci 2006;2:167-70.

11. Supriyadi E. Sutaryo. Status Gizi sebagai faktor prognostik pada leukemia limfoblastik Akut di RSUP dr. Sardjito [Tesis]. Yogyakarta: Universitas Gadjah Mada; 2001.

12. Halton JM, Atkinson SA, Barr RD. Growth and Body Composition in Response to Chemotherapy in Children wit Acute Lymphoblastic Leukemia. Int J Cancer Supple 1998;11:81-4.

Paediatr Indones, Vol. 48, No. 1, January 2008 • 31 
Fransiska Herintya et al: Nutritional state and outcome of acute lymphoblastic leukemia

13. Pearce JM, Sils RH. Childhood Leukemia. Pediatric Review 2005;26:96-104.

14. Smith M, Arthur D, Camitta B. Uniform approach to risk classification and treatment assignment for children with acute lymphoblastic leukemia. J Clin Oncol 1996;14:1824. 